\title{
DOCENTES EM FORMAÇÃO E AS SIGNIFICAÇÕES PRODUZIDAS EM TORNO DO ENSINO SUPERIOR
}

\author{
LECTURERS UNDERGOING TRAINING \\ AND THE MEANINGS PRODUCED ABOUT \\ UNDERGRADUATION
}

Francisco André Silva Martins ${ }^{1}$, Maíra Tomayno de Melo Dias Azevedo ${ }^{2}$, Symaira Poliana Nonato ${ }^{3}$

\section{RESUMO}

O presente artigo tem como objetivo apresentar uma discussão sobre as significações produzidas por docentes em formação em torno do(a) professor(a) universitário(a) e da docência no ensino superior, no contexto atual das políticas públicas federais. Para tanto, realizamos uma análise dos comentários feitos em torno do tema pelos alunos do Curso de Formação em Docência no Ensino Superior, ofertado pela

${ }^{1}$ Licenciado em História, Mestre em Educação, Doutorando em Educação (FaE/ UFMG).

${ }^{2}$ Pedagoga, Mestre em Educação, Doutoranda em Educação (FaE/ UFMG).

${ }^{3}$ Pedagoga, Mestre em Educação (FaE/UFMG).
Rede de Desenvolvimento de Práticas do Ensino Superior (GIZ) no fórum de discussão do ambiente virtual de aprendizagem. Ao final, ressaltamos que não é possível traçar um perfil do professor ideal, mas sim discutir as inúmeras significações produzidas para esse "novo" professor, especialmente sob a ótica de estudantes de pós-graduação, que se encontram na linha tênue entre ser aluno e ser professor. Pretendemos, ainda, tornar visível a necessidade de investimentos na formação dos profissionais que atuam nesse nível de ensino.

Palavras-chave: Docência. Ensino Superior. Professores. 


\section{INTRODUÇÃO}

O presente artigo evidencia uma discussão sobre as significações produzidas por docentes em formação em torno do(a) professor(a) universitário(a) e da docência no ensino superior, no contexto atual das políticas públicas federais. Denotamos que, cada vez mais, novos elementos parecem ser primordiais para "tornar-se docente". Selma Pimenta e Léa Anastasiou (2010) chamam a atenção para a necessidade de formação contínua ou em serviço para os professores do ensino superior, pois ainda é frequente a ideia de que para atuar nesse segmento de ensino não é necessário ter competências didático-pedagógicas. Tal questão é um tanto quanto complexa, tendo em vista que a própria Lei de Diretrizes e Bases da Educação Nacional (LDB) não estabelece tal formação como prioritária. Por outro lado, existem críticas a essa prerrogativa, especialmente aos que consideram que este é somente um dos elementos essenciais para o "fazer docente".

Consideramos essencial refletirmos sobre o professor universitário e a docência no ensino superior, sobretudo diante do contexto de mudanças pelas quais as universidades públicas têm passado, uma vez que este de certa maneira constitui o palco do nosso debate. Ressaltamos aqui o Programa de Reestruturação e Expansão das Universidades Federais (Reuni) ${ }^{1}$, implementado com o objetivo geral de expandir de forma significativa as vagas para estudantes de graduação no sistema federal de ensino superior. Outra ação do programa

\footnotetext{
${ }^{1}$ Ver Coelho (2012).
} 
estava voltada também para o aumento das vagas de pósgraduação, especialmente mestrado e doutorado. Diante dos objetivos descritos fez-se necessário criar estratégias para que eles fossem alcançados. Entre elas, enfatizamos:

Organização de equipes, constituídas por professores, bolsistas de pós-doutorado, bolsistas de doutorado e mestrado, para ministrarem as atividades de ensino de graduação. Os professores, em especial os de maior experiência, serão os responsáveis pela condução dessas equipes e pelo desenvolvimento mais geral das disciplinas. Subdivididas em grupos menores, para aulas de discussão, de estudo dirigido, de resolução de problemas e de laboratório, sob a responsabilidade de parte da equipe, as turmas assim compostas propiciarão um acompanhamento mais individualizado dos estudantes (UFMG-REUNI, [s.d.]).

De acordo com a proposta de implantação do Reuni desenvolvida pela Universidade Federal de Minas Gerais (UFMG), é possibilitada aos pós-graduandos a oportunidade de se preparar para atuar no ensino superior, o que foi considerado uma contribuição adicional para melhorar a qualidade da formação do docente. Assim aparece a figura do "bolsista Reuni", que recebe uma bolsa e um valor monetário adicional vinculado à Pró-reitoria de Graduação para apoiar atividades de ensino junto à equipe de professores na graduação.

Como consequência desse contexto de expansão e mudanças nos processos metodológicos na área do ensino superior, pressupostos pelo Reuni, a universidade cria o GIZ (Rede de Desenvolvimento de Práticas do Ensino Superior). Essa ação está vinculada à Pró-reitoria de Graduação e tem como 
finalidade o aprimoramento das metodologias de ensino superior por meio do uso das novas tecnologias de informação. Entre as diferentes atividades desenvolvidas pelo GIZ, destacase o Curso de Formação em Docência no Ensino Superior, do qual fazemos parte. Idealizado especialmente para atender a uma demanda de expansão, o curso é destinado a alunos de pós-graduação stricto sensu e seu objetivo geral é: "Discutir os desafios e perspectivas da educação superior visando identificar e promover as habilidades necessárias para que o docente amplie e consolide sua competência didática na docência do ensino superior" (GIZ/UFMG). Inicialmente, o curso era aberto a todos os alunos da pós-graduação. Contudo, devido às novas demandas impostas pelo Reuni, passou a dar prioridade a alunos "bolsistas Reuni" e tornou-se condição para o exercício da bolsa.

O curso tem carga horária de 60 horas, das quais 20h/a presenciais e 40h/a em atividades no ambiente virtual de aprendizagem, via plataforma Moodle. O início do curso é marcado por uma aula inaugural, na qual é realizada atividade sobre o(a) professor(a) universitário(a) no contexto atual. Após a aula inaugural os alunos são convidados a continuar a conversar sobre tal temática no ambiente virtual de aprendizagem.

Considerando o objetivo geral deste artigo, já pontuado, traçamos um breve percurso histórico sobre a constituição do ensino superior no Brasil, com destaque para a conjuntura atual. Primeiramente, faremos uma contextualização do ambiente do curso e das atividades analisadas. Após, com base na discussão realizada no ambiente virtual de aprendizagem 
pelos estudantes de pós-graduação de três turmas diferentes, nos turnos da manhã, tarde e noite, nas quais fomos tutores(as), buscaremos identificar características do(a) professor(a) universitário(a) e da docência no contexto atual de acordo com o que foi enfatizado pelos alunos. Por fim, é importante ressaltar que não ensejamos traçar um perfil do professor ideal, mas sim discutir as inúmeras significações produzidas em relação a esse "novo" professor, principalmente sob a ótica de estudantes de pós-graduação, que se encontram na linha tênue entre ser aluno e ser professor.

\section{ALGUMAS QUESTÕES EM TORNO DA DOCÊNCIA NO ENSINO SUPERIOR}

Para avançarmos no entendimento e apropriação das discussões que serão realizadas faremos uma breve retomada histórica do ensino superior no Brasil. Segundo Maria Izabel da Cunha (2011, p. 22), a instituição educacional é "contextualizada, isto é, sua realidade, seus valores, sua configuração variam segundo as condições histórico-sociais que a envolvem". E nesse contexto o professor é determinante da instituição, mas também é determinado por ela.

Tendo como parâmetro de comparação a América Espanhola, podemos dizer que no Brasil a universidade chegou em tempos recentes, há pouco mais de 200 anos. Enquanto na colônia espanhola as universidades se estabeleceram desde 1538, na colônia portuguesa isso somente ocorre a partir de 1808, com a vinda da Família Real para o Brasil (PIMENTA; ANASTASIOU, 2010). A inexistência de universidades por tão longo período se deveu ao perigo, para a metrópole, quanto à possibilidade 
de fomentar naquele ambiente discussões que envolvessem a quebra do pacto colonial e o rompimento com Portugal. Até então a saída para as elites brasileiras que primavam pela formação dos filhos era mandá-los para estudar na Europa (FAUSTO, 2006).

Segundo Maria de Lourdes Coelho (2012), percebe-se de forma destacada a opção por alguns modelos de universidade de acordo com o período histórico das instituições brasileiras. Inicialmente, perpassando o século XIX, o modelo adotado foi o francês ou napoleônico, que privilegiava uma organização profissionalizante dos cursos e que aqui se deu por meio de faculdades isoladas. $O$ intuito era de formar profissionais burocratas para desempenhar as funções do Estado. Esse modelo primava por um corpo docente fixo, os professores eram verdadeiros transmissores do conhecimento que nos estudos dos clássicos centralizavam o saber na memorização de conteúdo e na sua efetiva comprovação por meio de avaliação essencialmente classificatória.

Na transição do século XIX para o XX, emerge na Alemanha o modelo humboldtiano, que também influenciará as instituições brasileiras. Sob esse modelo, a universidade possibilita a edificação nacional, as pesquisas têm como intuito a renovação tecnológica de um país que estava à reboque da Inglaterra e da França no processo de consolidação da Revolução Industrial. Essa instituição, que primava pela resolução de problemas nacionais, tinha como intuito unir professores e alunos em torno da pesquisa (PIMENTA, ANASTASIOU, 2010). Esse era um modelo no qual "docência e pesquisa eram concebidas como 
atividades livres e criativas, desenvolvidas cooperativamente entre professores e alunos" (COELHO, 2012, p. 45).

A década de 30 do século XX é marcada pelo surgimento da Universidade de São Paulo (USP), que trazia consigo duas bandeiras: a integração das áreas do conhecimento e a produção efetiva de pesquisas pelos alunos e professores. O intuito seria de formar o pesquisador, o cidadão e o profissional. A metodologia proposta previa a formação de um grupo pequeno de alunos que investigava temas específicos de forma cooperativa. No ano de 1938 a preocupação com a formação do cidadão se restringiu às questões técnicas e a preocupação se voltou para atividades isoladas de professores em aula (MASETTO, 2012).

O ano de 1968 marca o ensino superior brasileiro em função da emergência de uma forte influência do sistema de ensino norte-americano, que, baseado, em certa medida, no modelo alemão, dava destaque à produção do conhecimento e ao processo de pesquisa. $O$ acordo estabelecido entre o Ministério da Educação (MEC) do Brasil e a United States Agency for International Development (USAID), no texto da Lei 5.540/68, promove a separação entre ensino e pesquisa. Isto é, sob os auspícios da graduação fica a formação do profissional e sob os cuidados da pós-graduação, a pesquisa.

As universidades brasileiras funcionaram sob a influência das mudanças promovidas na ditadura militar até meados da década de 1990. Os resquícios do modelo francês e as marcas deixadas pelo modelo estadunidense influenciaram de tal maneira as instituições educacionais superiores do país que ainda hoje se crê plenamente na premissa de que quem 
sabe alguma coisa, automaticamente, sabe ensinar, que quem exerce bem uma profissão pode ensinar sobre essa profissão, situação que pode resultar na construção de um verdadeiro sofisma (MASETTO, 2012).

Até há muito pouco tempo, os professores universitários no Brasil eram convidados a lecionar em função do exercício bem-sucedido da profissão. Segundo Selma Pimenta e Léa Anastasiou (2010), o exercício da docência superior carrega consigo uma valorização social que é explicitada pelos profissionais em seus cartões pessoais, nos consultórios e escritórios. Contudo, o título de professor, isoladamente, é considerado algo menor, em função de parecer se referir aos professores da educação básica, um problema que envolve a docência superior tanto no que se refere à identidade quanto à profissão.

Ao tomarmos como base a legislação vigente, LDB Lei 9.394/96, vemos que ainda prevalece, em certa medida, a concepção de que, para atuar no ensino superior, o profissional não necessite de conhecimentos específicos de cunho didático e pedagógico (GATTI; BARRETTO, 2009). Enquanto a atuação na educação básica envolve obrigatoriamente disciplinas relacionadas à prática de ensino, na educação superior a exigência é unicamente a da pós-graduação, prioritariamente, em nível de mestrado e doutorado.

Se entendermos que nesses níveis a pós-graduação tem como foco a pesquisa, fica claro que as questões didáticas e pedagógicas se apresentam como de menor importância diante da notoriedade alcançada pela pesquisa. As maiores preocupações dos pós-graduandos giram em torno de publicar 
os resultados da pesquisa, participar de congressos, publicar artigos, escrever livros - atividades tidas como de primeira ordem para quem está no mestrado ou doutorado e que vão intervir fortemente no seu currículo pessoal e nos concursos públicos a que se submeterá no futuro. A preocupação se volta para o profissional que vai atuar como docente, para a sua especialização, mas não para a profissionalização e o aprimoramento do docente. Ou seja, munir o professor das capacidades pedagógicas e didáticas para conseguir promover o aprendizado dos alunos e a construção do conhecimento não é uma das preocupações centrais dos programas de mestrado e doutorado.

Contudo, algo que pode soar como paradoxal é a relação do próprio Estado para com tais instituições e profissionais. Apesar de o sistema não estabelecer princípios e diretrizes para a formação do professor do ensino superior, no que se refere ao pedagógico e didático, a performance dos alunos nas avaliações externas é ainda o maior indicador de qualidade (PIMENTA; ANASTASIOU, 2010). Nesse sentido, o Estado relega às próprias instituições educacionais o debate e a resolução das questões em torno do processo de formação e docência, bem como da formação dos alunos e de seu papel social.

\section{O CENÁRIO DA FORMAÇÃO}

Para contextualizar o debate proposto, realizaremos uma descrição da aula inaugural do Curso de Formação em Docência no Ensino Superior, pois a temática anunciada está intimamente relacionada à constituição desse evento, bem como às atividades realizadas pelos cursistas ao longo 
desse encontro. Destacamos uma das propostas, que tem como objetivo principal conhecer as significações produzidas pelos alunos em torno do(a) professor(a) universitário(a). Essa atividade tem continuidade na plataforma virtual Moodle, nos fóruns de discussão. Nossa análise centra-se nos desdobramentos dessa atividade e sua articulação à formação docente no ensino superior.

No primeiro contato estabelecido com os pós-graduandos, procuramos apresentar o curso, sua organização, funcionamento e estrutura. Dessa forma, na abertura da aula inaugural do $2^{\circ}$ semestre de 2012, a diretora do GIZ, professora Juliane Corrêa, explicou que o objetivo da Rede de Desenvolvimento de Práticas do Ensino Superior é assessorar e implementar o uso de novas tecnologias e metodologias no âmbito dos cursos de graduação do Reuni e destacou as ações realizadas pelo GIZ no contexto da UFMG. O Curso de Formação em Docência Superior é uma delas. Destina-se aos mestrandos, doutorandos e pós-doutorandos das diversas áreas inseridas no programa Reuni, que prevê a distribuição de bolsas Capes, com dedicação de oito horas semanais, sob acompanhamento de um docente.

Em seguida, foram apresentados pela coordenadora, professora Zulmira Medeiros, o calendário e o conteúdo programático do curso, que abrange a docência no ensino superior e a identidade do docente na universidade, as concepções de ensino e aprendizagem, o planejamento de ensino, a avaliação da aprendizagem e tecnologias e recursos didáticos. Nesse momento, os cursistas também tiveram a oportunidade de conhecer o ambiente virtual no qual estudariam e obter 
algumas explicações relativas ao seu funcionamento. A equipe de tutores foi apresentada e uma das integrantes do grupo, a professora Maria de Lourdes Coelho, proferiu palestra sobre os processos de constituição da docência universitária, destacando a implantação do Reuni na UFMG. Essa discussão é fruto de sua tese de doutorado e contribui muito para que os cursistas possam compreender um pouco mais o contexto em que atuarão. Coelho investigou o processo de formação docente diante das diretrizes, práticas e estratégias adotadas nesse campo pelas universidades públicas.

Após a palestra, os cursistas foram convidados a participar de uma atividade em grupo. A formação dos grupos aconteceu de forma aleatória, entregando-se a cada participante, no início do evento, uma ficha com o número do grupo de que faria parte. Após receberem a orientação sobre a organização, os estudantes se dirigiram ao local indicado: o saguão do auditório. Nesse espaço, disponibilizamos para cada grupo o material para a elaboração dos cartazes, como papel kraft, caixa de giz de cera, pincéis atômicos de cores variadas e um impresso contendo as especificações da atividade.

Os participantes de cada grupo reuniram-se em torno do material e fizeram uma breve apresentação pessoal. Após lerem as orientações, partiram para a execução da atividade: uma das integrantes do grupo deitou-se sobre a folha de papel kraft e teve o contorno do seu corpo desenhado por outro participante com um pincel atômico, como mostra a Figura 1. 


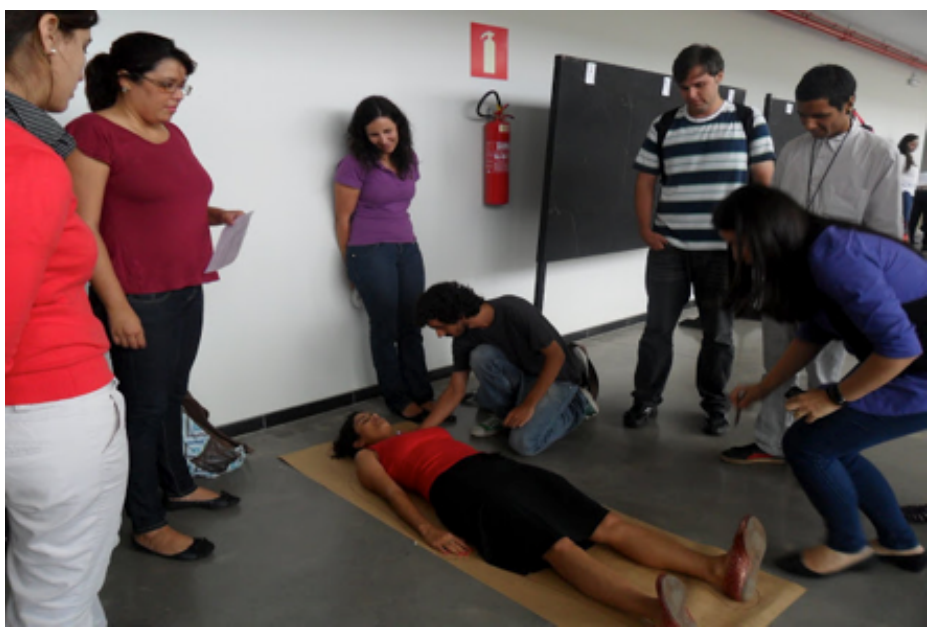

Figura 1 Desenhando o contorno do corpo

Como não podiam conversar entre si, todos registraram, por meio de desenhos e expressões, as imagens trazidas sobre o(a) professor(a) universitário(a). Após 20 minutos, os grupos finalizaram a atividade e se movimentaram no saguão para apreciar as produções dos colegas.

Em seguida, todos retornaram para o auditório e apresentaram os cartazes. Foi escolhido um representante para cada grupo, que ficou responsável por destacar as principais características atribuídas ao professor. Conforme observado por Maria de Lourdes Coelho (2012), vários elementos se repetem, tais como: um coração representando a paixão pelo ensino, o uso de relógio sinalizando a falta de tempo para conseguir articular múltiplas funções, a preocupação com as publicações e a desvalorização do profissional docente. Além disso, a maioria 
dos desenhos retratou o professor por meio da figura de um homem, ainda que a silhueta tivesse sido traçada a partir do corpo de uma mulher, como vemos nas Figuras 1 e 2.

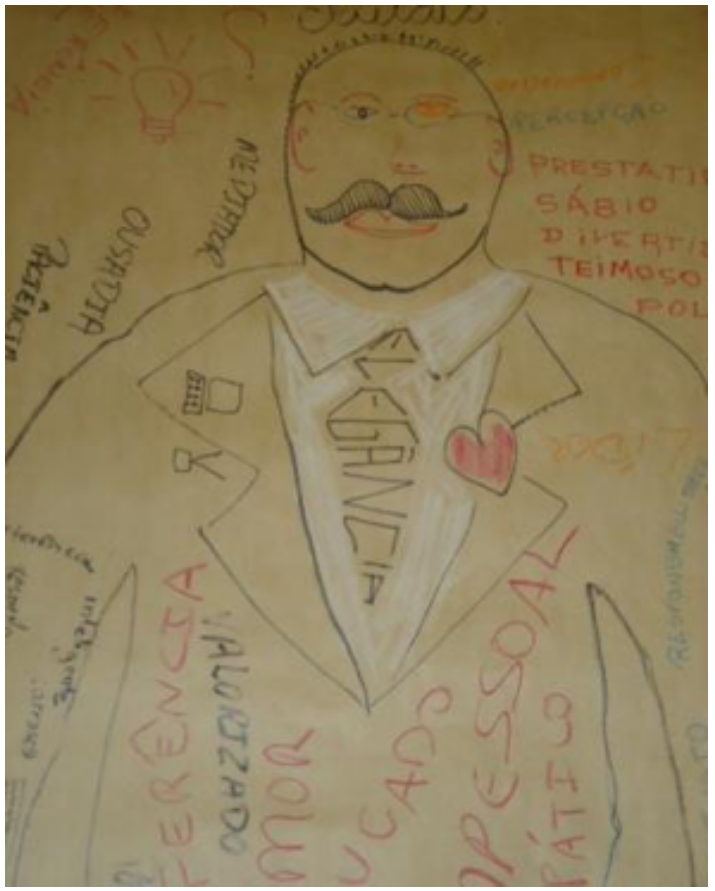

Figura 2 Caracterização finalizada

Após as apresentações dos cartazes, os professores-tutores, com a participação dos cursistas, fizeram o levantamento dos elementos que se repetiram ou as características preponderantes do professor(a) representado(a) graficamente. 


\section{A CONSTRUÇÃO DE SIGNIFICADOS PARA A DOCÊNCIA NO ENSINO SUPERIOR}

Conforme Maria de Lourdes Coelho (2012), esse exercício lúdico suscitou o questionamento sobre o que é ser professor universitário e, como mencionado, a discussão prosseguiu no fórum criado no ambiente virtual de aprendizagem. Por meio dessa ferramenta, os pós-graduandos acessaram textos sobre o tema, compartilharam experiências e visualizaram os desenhos produzidos pelos colegas no dia da aula inaugural. Dessa forma, mesmo aqueles que não puderam comparecer ao encontro presencial tiveram contato com as produções coletivas.

Todas as turmas seguiram o mesmo planejamento, ao todo foram cinco ofertas, distribuídas da seguinte forma: A1 manhã; B1, B2 e B3 tarde; e C1 noite. Essa divisão foi necessária para garantir a realização dos encontros presenciais que aconteceram ao longo do curso. Para facilitar o trabalho de análise, realizamos um levantamento de todos os comentários feitos pelos alunos nas turmas A1, B2 e C1. Essa escolha devese ao fato de que nós estávamos realizando o trabalho de tutoria nessas turmas.

O fórum de discussão sobre a docência universitária ocorrido no ambiente de cada turma do curso iniciou com a seguinte mensagem postada no Módulo 2 - Docência na Universidade:

Olá, tod@s!!!

Acessem as Fotos da Aula Inaugural através do arquivo em anexo e vejam os cartazes dos/as "professores/as universitários/as" desenhados/as 
e algumas características ressaltadas pelos grupos. Agora convidamos os que estiveram presentes e os ausentes a apreciar cada uma das imagens, destacar as características mais marcantes e responder às seguintes questões: Qual imagem mais chamou a sua atenção? Por que motivo? Que sentimento surgiu ao ver essas imagens ou ao participar da vivência de elaboração dos cartazes? Como você percebe o seu processo de formação diante dos perfis ali expostos?

Ao verificarmos o teor das respostas, analisamos os temas relevantes para os docentes em formação. Como apontado por muitos cursistas, na conjuntura atual, os professores encontram-se em uma situação, muitas vezes, de crise:

Percebe-se nessa figura que este professor encontrase sobrecarregado com tantas tarefas (leituras mil, prazos, aulas, projetos, dentre outros) e por isso também demonstra ser um pouco exigente com seus alunos. Isso fica claro no diálogo com os alunos que está ilustrado. 0 professor diz para os alunos: estudar capítulo 1 a 20. Alunos respondem: Mas, professor, temos outras matérias para estudar. Professor: o que você faz de meia-noite às seis? (Luciana, ${ }^{2}$ mestranda).

O problema é encaixar tantos pré-requisitos fundamentais (fazer pesquisa, ter jogo de cintura, etc.) a esse perfil, buscando sempre ser mestre na vida dos nossos alunos (Carina, doutoranda).

Todas as caricaturas me passam a imagem de um profissional sobrecarregado por múltiplas responsabilidades: a docência em todas as suas instâncias (o que significa em pôr em prática todos os seus conhecimentos em didática, psicologia, política

\footnotetext{
2 Para preservar a identidade dos sujeitos envolvidos utilizaremos nomes fictícios.
} 
e filosofia da educação, tanto no que diz respeito às escolhas profissionais, quanto no que diz respeito à sua atuação em sala de aula), a pesquisa (que no seu ideal demanda um certo grau de imersão e dedicação), a educação humana além da profissional (que reproduz todas as instâncias da docência, mas com outros critérios). Enfim, tudo isso em um nível de exigência mais elevado por ser voltado para o ensino superior. A administração de todas estas instâncias é o que eu acho que faz o professor universitário ter aquelas características estereotipadas em muitas caricaturas: criatividade, jogo de cintura, paciência, reflexividade... (Júlio, doutorando).

Diante de tantas demandas, urge a necessidade de repensarmos a atuação do professor universitário, existencial e profissionalmente, uma vez que sua formação para pesquisa, que é notoriamente reconhecida como importante, pode não ser o suficiente para o exercício da docência da maneira desejável. A academia, na sua forma organizacional, amalgama hierarquias que relegam ao ensino um status menor em comparação com a pesquisa. No curso de formação ofertado pelo GIZ, várias foram as vezes que os cursistas problematizaram a questão de professores que são exímios pesquisadores, que se destacam notoriamente no mundo acadêmico, mas que têm dificuldade de proporcionar ao seu aluno a apropriação do conhecimento. Os alunos destacaram também a importância da complementaridade dessas duas ações:

Penso que o ensino precisa ser alimentado pela pesquisa, e esta precisa se dar em diálogo constante com a realidade educacional. $O$ ensino sem pesquisa fica cristalizado, ultrapassado, distanciado das reais necessidades requeridas pelo processo de ensino e aprendizagem. Por sua vez, a pesquisa apartada dos problemas da realidade, das necessidades da prática, não funciona de maneira efetiva na transformação 
do processo educacional. Além disso, há que se ter um diálogo com a comunidade, a partir de ações extensionistas, o que permite perceber a pluralidade de demandas advindas de contextos também plurais (Nara, doutoranda).

Os alunos do curso de docência do ensino superior - todos cursando pós-graduação stricto sensu e que em sua maioria emendaram a graduação, o mestrado e o doutorado explicitaram nas discussões o fato de estarem se tornando excelentes pesquisadores, mas terem dificuldade de ensinar, de lidar com o papel de professor. Apesar de a formação conduzi-los, quase que obrigatoriamente, à sala de aula de uma universidade, as questões de cunho didáticos e pedagógicos Ihes são praticamente desconhecidas. Essa é uma realidade vivida pela maioria dos docentes do ensino superior, segundo Masetto:

Recentemente, professores universitários começaram a se conscientizar de que seu papel de docente do ensino superior, como o exercício de qualquer profissão, exige capacitação própria e específica que não se restringe a ter um diploma de bacharel, de mestre ou doutor, ou apenas o exercício da profissão. Exige isso tudo e competência pedagógica, pois ele é um educador, alguém que tem a missão de colaborar eficientemente para que seus alunos aprendam. Esse é seu ofício e compromisso. Para se desempenhar bem esse papel, o professor necessita de uma formação pedagógica. Entendese, então, que ainda tem sentido o debate dessa temática (MASETTO, 2012, p. 15).

Os cursistas problematizaram essa questão em suas reflexões:

A imagem que mais me chamou a atenção foi também a do Capetão. Essa figura me lembrou 
que existem professores, que, infelizmente, parecem desconhecer os princípios da prática do ensino superior e tentam impor aos alunos um conhecimento unidirecional, onde o aluno é apenas um executador do que está sendo ensinado (Cecília, mestranda).

Dada a complexidade da sociedade na qual estamos inseridos, na qual o acesso à informação é totalmente desproporcional à capacidade humana de assimilação e as fontes de produção não mais se restringem ao ambiente acadêmico, o papel do professor não é mais o do detentor do saber total, óbvio que se espera dele o domínio de uma área do conhecimento, mas, concomitante a isso, também se espera a compreensão de situações que ultrapassam uma especialidade, espera-se uma capacidade de interação social, entre pessoas, entre áreas, entre disciplinas. Entretanto, alguns alunos questionaram o exercício dessa integração em suas experiências:

Apesar de algumas falas e desenhos trazerem a ideia de professor como sujeito que se relaciona com os outros, o trabalho que predomina parece ser o individual (Tiago, mestrando).

Esse turbilhão de questões nos remete a uma discussão que coloca em primeiro plano o ofício do docente e a responsabilidade que envolve a profissão. Nesse contexto, o curso do GIZ assume um papel central, ou seja, o de proporcionar aos alunos de pós-graduação da UFMG, pouco que seja, uma discussão em torno da docência do ensino superior? Obviamente que não! Seria ingenuidade tamanha pretensão. Contudo, não obstante a quantidade de horas, percebemos o quanto esse espaço tem proporcionado questionamentos que levam os alunos a procurar por seus 
caminhos próprios, tentar outras saídas, pensar sobre o seu fazer profissional. Nós, membros da equipe de formação, temos plena consciência das nossas limitações, mas temos consciência também que, minimamente, estamos inquietando os alunos, tirando-os da zona de conforto, propondo-lhes discutir conosco essas questões.

Miguel Arroyo (2011), ao investigar o ofício do mestre, mesmo que em seu estudo privilegie a educação básica, permite-nos problematizar aspectos importantes do fazer docente. Não nos formamos somente mediados por livros e manuais, pelo estudo das disciplinas, nas quais, de maneira excepcional, fazemos o impossível para obter conceito máximo. Aprendemos, sobretudo, convivendo, experimentando, sentindo.

Representamos um papel social influenciado pela nossa história de vida e, nesse contexto, lembramos de cada um dos professores que passaram por nós, os bons e os ruins, e levamos conosco ensinamentos. Em vários momentos, pudemos perceber que os alunos do curso de formação fizeram esse exercício de comparação entre o perfil dos professores que já tiveram e o ideal que almejam alcançar. Muitos destacaram as mudanças pelas quais o exercício da docência vem passando ao longo do tempo:

Essa figura me lembrou que existem professores que, infelizmente, parecem desconhecer os princípios da prática do ensino superior e tentam impor aos alunos um conhecimento unidirecional, onde o aluno é apenas um executador do que está sendo ensinado. No curso de Odontologia, como o meu, vivenciei isso em algumas práticas ministradas por determinados professores. Uma pena (Julia, doutoranda). 
A maioria das figuras trouxe a percepção de professores ditadores, normativos, inflexivos. A figura do prof. com o giz na mão chama atenção para a sua representação perante a classe, ou seja o prof. é o protagonista e os alunos, os ouvintes. Infelizmente essa figura é bastante presente em nosso meio (João, mestrando).

A imagem que mais me chamou a atenção também foi a do "capetão"! Não tenho encontrado atualmente este tipo de professor. Concordo com a Mariana, acho que este perfil de professor era encontrado mais antigamente, quando o ensinoaprendizagem era vertical e o aluno era somente o ouvinte! Acho que se ainda persiste este tipo de professor é porque a insegurança predomina. Este professor, que não dialoga com o aluno, é aquele inseguro que não permite (por medo) que o aluno tenha um comportamento reflexivo diante do conhecimento! (Fernanda, mestranda).

Os próprios alunos tomaram esse exercício de evocação como objeto de reflexão e acentuaram ainda a responsabilidade do professor perante o aluno:

O que percebi foi que cada grupo trouxe as experiências que tiveram quando alunos e as expectativas que têm para quando se tornarem professores. Isso me fez refletir sobre a importância do professor na formação do aluno (Carlos, doutorando).

Em geral, os desenhos trazem referências e características que misturam o ideal do professor e a imagem real do mesmo. Algumas características parecem nos acompanhar desde a infância e os primeiros anos da vida estudantil. Os corações me lembraram o carinho e atenção das "tias" do primário. Os óculos e livros, presentes em vários desenhos, também são imagens associadas ao 
estudo e, portanto, ao professor. Se as imagens me lembraram os professores do ensino fundamental e médio, com os dizeres me lembrei dos professores da graduação e da pós-graduação, envolvidos com ensino, pesquisa, extensão e assuntos administrativos (Carine, mestranda).

Arroyo (2011) considera que não nascemos professores, a formatura pode nos documentar como professor, proporcionar um diploma, mas na verdade temos de aprender a ser professores no exercício da profissão, em que a realidade é sempre mais dura que na teoria. Nas palavras do autor:

Os mestres formados em nossos centros podem ter decifrado todos esses símbolos tão redundantes, porém a relação entre eles e seu ofício no cotidiano escolar restará incerta. Um emblema que carregarão cada dia, em sua mochila de professor(a), a cada viagem de ida e volta do seu lugar de trabalho (ARROYO, 2011, p. 134).

Assim como a teoria hermética não dá conta das demandas sociais colocadas para a educação nos vários níveis, as práticas, se estagnadas, também não avançam no que concerne à construção do conhecimento como capacidade crítica. Articulação entre teoria e prática, no sentido amplo das palavras, essa é a tarefa hercúlea imposta aos corajosos que optam por caminhar na senda da docência. Segundo Cunha (2011):

O conhecimento do professor é construído no seu próprio cotidiano, mas ele não é só fruto da vida na escola. Ele provém, também, de outros âmbitos e, muitas vezes, exclui de sua prática elementos que pertencem ao domínio escolar. A participação em movimentos sociais, religiosos, sindicais e comunitários pode ter mais influência no cotidiano 
do professor que a própria formação docente que recebeu academicamente. Há uma heterogeneidade na vida cotidiana do professor manifesta pelas incongruências, saberes e práticas contraditórias e ações aparentemente inconsequentes. É preciso recuperar esse aspecto heterogêneo ao invés de eliminá-lo, na tentativa de enquadrá-lo em tipologias previamente definidas. Ao contrário, a riqueza, muitas vezes, está no heterogêneo e é preciso reconhecê-lo como produto de uma construção histórica (CUNHA, 2011, p. 34).

Diante do exposto, no intuito de melhor discutirmos as questões que envolvem o professor universitário, achamos importante nos aproximarmos das discussões de Maurice Tardif (2005), ao tratar da epistemologia da prática profissional. Segundo o autor, esse é "o estudo do conjunto dos saberes utilizados realmente pelos profissionais em seu espaço de trabalho cotidiano para desempenhar todas as suas tarefas" (TARDIF, 2005, p. 255, grifos do autor). Esse pode ser entendido como um movimento no qual a busca é por ampliar a noção de "saber", buscando englobar os conhecimentos, as competências, as habilidades e as atitudes, o que segundo o autor foi chamado, muitas vezes, de saber, saber-fazer e saberser. Nesse sentido:

O trabalho não é primeiro um objeto que se olha, mas uma atividade que se faz, e é realizando-a que os saberes são mobilizados e construídos. Este enfoque considera que o profissional, sua prática e seus saberes não são entidades separadas, mas "copertencem" a uma situação de trabalho na qual "coevoluem" e se transformam (TARDIF, 2005, p. 257).

Em função disso, uma consequência direta da epistemologia da prática profissional é que não se deve confundir os 
saberes profissionais com os conhecimentos transmitidos e apropriados no âmbito da universidade. O autor destaca que os profissionais que tiverem a docência como horizonte de atuação devem romper com o hermetismo dos gabinetes universitários e procurar submergir na realidade da instituição escolar, no chão da sala, sendo esse um espaço de ação, interação, tensão. O professor não é apenas determinado pela realidade que o cerca, mas também um ator social que detém saberes e um saber-fazer.

Os próprios alunos sentem essa necessidade de articulação e afirmam:

\footnotetext{
Mais do que passar o conteúdo, o professor tem o papel de ligação entre a teoria da sala de aula e a prática que será vivenciada após a graduação, e isso envolve segurança, habilidade, paciência... (Carla, doutoranda).
}

Na minha opinião existe uma grande diferença entre um professor e um mestre. Um professor "apenas" ensina uma disciplina, um conteúdo. Enquanto um mestre provoca mudança, ensina algo que você levará para a vida! (Milena, mestranda).

De posse de algumas das questões que envolvem o professor, passemos a algumas questões importantes relativas à docência enquanto prática social: o ensino e a aprendizagem. Pimenta e Anastasiou (2010) destacam que muitas vezes esses termos, por si sós, não dão conta da complexidade que abrange a docência do ensino superior.

Muitas vezes, o ensino nos cursos superiores se restringe a aulas magnas, palestras, exposições intelectuais, o que promove 
aulas enfadonhas, boas para dormir e que desconsideram que a ação de ensinar conduz, de acordo com os fins educacionais, obrigatoriamente, à ação de aprender. "Portanto, a prática social complexa efetivada entre os sujeitos professor e aluno em sala de aula engloba tanto a ação de ensinar quanto a de aprender" (PIMENTA; ANASTASIOU, 2010, p. 205). Essa proposta difere daquelas que percebem a aprendizagem como alcance de metas e implicam intencionalidade de êxito, uma vez que nem sempre a aprendizagem vem acompanhada do alcance da meta. Assim, as autoras nos sinalizam a ensinagem como caminho possível para as questões que envolvem o ensino e a aprendizagem.

Na ensinagem, a ação de ensinar é definida na relação com a ação de aprender, pois, para além da meta que revela intencionalidade, o ensino desencadeia necessariamente a ação de aprender. Essa perspectiva possibilita o desenvolvimento do método dialético de ensinar (PIMENTA; ANASTASIOU, 2010, p. 205).

Com base na discussão com outros autores, Pimenta e Anastasiou (2010) nos apontam aspectos singulares em se tratando da docência do ensino superior. Entre elas, há que se buscar entender que o ato de ensinar não se restringe à sala e ao momento da aula, a aprendizagem deve ser assumida como um processo de apropriação e aprimoramento ininterrupto. Logo, a busca é por romper com a noção de que ensinar se limita à exposição do conteúdo, muito difundida no senso comum. Na ensinagem, o ensino e a aprendizagem se amalgamam em uma unidade dialética. Ao professor cabe o papel de condutor da autoatividade do aluno, o que exige a provocação da aprendizagem mediante tarefas, atividades 
interações. Do aluno se exigem a compreensão, descoberta, construção de sentidos e rede de relações em torno do que é novo.

Dessa forma, a relação entre professores e alunos é modificada:

Achei muito interessante a pesquisa da Simone e acredito que o nosso grande desafio é justamente refletir e implementar uma nova "relação pedagógica", como nos lembrou a Symaira. Penso que uma das grandes dificuldades é a própria posição do aluno, que vem do ensino médio e fundamental com uma visão tradicional de seu papel e do papel do professor. O aluno chega "enquadrado" e se coloca, muitas vezes, como "alguém sem luz". É nosso desafio então abalar essas incompreensões e tentar estabelecer uma relação não hierárquica, mais dialógica (Marina, mestranda).

A relação entre aluno e professor melhorou, os professores estão mais preocupados com o aprendizado e a opinião do aluno (Luiz, doutorando).

Nota-se que o desafio colocado está em romper com o modelo no qual o professor tem o papel principal, o detentor do conhecimento a ser reproduzido e memorizado pelos alunos, e partir para a percepção dos alunos para além de coadjuvantes, percebê-los como aqueles que se informam, se exercitam e se instruem (GIL, 2011; 2012), uma perspectiva que já não se comporta nas fronteiras de simplesmente "assistir a aulas".

\section{CONSIDERAÇÕES FINAIS}

Neste artigo, analisamos as significações produzidas por docentes em formação, mestrandos e doutorandos, em torno 
da docência no ensino superior, levando em conta o contexto de expansão e reestruturação proposto pela UFMG. Sabemos que a universidade é o espaço privilegiado de construção de conhecimento e que esse processo envolve diferentes elementos constitutivos.

Ao buscarmos respostas sobre o que é ser professor(a) universitário(a) atualmente, verificamos que a maioria dos alunos ressalta: a necessidade de formação específica para o docente no ensino superior; a dificuldade de conciliação entre as diversas atribuições do professor no modelo que traz o ensino, a pesquisa e a extensão numa relação triádica; a constante mudança na relação entre professores e alunos, considerados sujeitos ativos e principais do processo de ensinoaprendizagem; o domínio de aspectos didático-pedagógicos.

Dessa forma, a reflexão sobre a docência no ensino superior nos remete ao debate sobre o processo de formação para tal, considerando seus aspectos teóricos e práticos. Por meio das atividades propostas e das respostas dos alunos, buscamos compreender como nos tornamos docentes e que repertório de saberes é necessário para uma atuação cada vez mais qualificada.

A não exigência legal de uma grade curricular que privilegia a formação para exercer a docência e a consequente falta de preparo dos cursos de pós-graduação para formar esses profissionais, conforme apontado pelos próprios alunos, constituem uma preocupação, mas são, ao mesmo tempo, a constatação necessária para uma mudança. 
Nesse sentido, pretendemos tornar visível a necessidade de investimentos na formação docente dos profissionais que atuam nesse nível de ensino. Como mencionado não há uma exigência legal para exercer tal atividade, entretanto a formação dos professores que atuam no Ensino Superior apresenta-se como uma preocupação atual, já que, conforme apontado pelos próprios alunos, os cursos de pós-graduação, têm demonstrado uma falta de preparo para formar esses profissionais no aspecto pedagógico.

\section{REFERÊNCIAS}

ARROYO, Miguel. Ofício de mestre: imagens e autoimagens. Petrópolis: Vozes, 2011.

COELHO, Maria de Lourdes. Processos de constituição da docência universitária: o REUNI na UFMG. 2012. Tese (Doutorado em Educação) - Programa de Pós-graduação em Educação, Faculdade de Educação, Universidade Federal de Minas Gerais, Belo Horizonte, 2012.

CUNHA, Maria Izabel. O bom professor e sua prática. Campinas: Papirus, 2011.

FAUSTO, Boris. História concisa do Brasil. São Paulo: Edusp, 2006.

GATTI, Bernardete Angelina; BARRETO, Elba Siqueira de Sá (Coord.). Professores do Brasil: impasses e desafios. Brasília: Unesco, 2009.

GIL, Antônio Carlos. Metodologia do ensino superior. São Paulo: Atlas, 2011. 
GIL, Antônio Carlos. Didática do ensino superior. São Paulo: Atlas, 2012.

MASETTO, Marcos Tarcísio. Competência pedagógica do professor universitário. São Paulo: Summus, 2012.

PIMENTA, Selma Garrido; ANASTASIOU, Léa das Graças Camargos. Docência do Ensino Superior. São Paulo: Cortez, 2010.

TARDIF, Maurice. Saberes docentes e formação profissional. Petrópolis: Vozes, 2005.

UFMG-REUNI. Reuni: o projeto final enviado. Disponível em: <http://www.ufmg.br/reuni/>. Acesso em: 5 maio 2013. 


\section{ABSTRACT}

This article aims at presenting a discussion about the meanings produced by lectures undergoing training about the university professor and undergraduation teaching in the current context of federal public policy. For this purpose, we performed an analysis of the comments made on the topic by the students from the Undergraduation Teaching Training, offered by the Undergraduation Practices Development Network (GIZ) in the virtual learning environment discussion forum. Finally, we emphasized that it is not possible to draw a profile of the ideal lecturer, but rather discuss the many meanings produced for this "new" professor, especially from the perspective of graduate students, who are on the fine line between being a student and being a lecturer. We also intend to make visible the need for investment in training of professionals who work at this level of education.

Keywords: Teaching. Undergraduation. Lecturers.

Artigo originalmente publicado em Revista Docência do Ensino Superior, v. 4, out. 2014. Disponível em <http://www.ufmg.br/giz>. 
